\title{
A linguagem como poder simbólico em um contexto de fronteiras: reflexões sobre a
}

\section{educação da língua espanhola}

\author{
Language as a symbolic power in a border context: reflections on spanish language education \\ La lengua como poder simbólico en un contexto de fronteras: reflexiones sobre la educación en \\ español
}

Recebido: 06/08/2021 | Revisado: 11/08/2021 | Aceito: 15/08/2021 | Publicado: 17/08/2021

\author{
Raquel Blankenheim de Brito Keller \\ ORCID: https://orcid.org/0000-0002-5035-1189 \\ Universidade Estadual do Oeste do Paraná, Brasil \\ E-mail: kel_bk@ @otmail.com \\ Thayane Ellen Machado da Silva \\ ORCID: https://orcid.org/0000-0002-7253-1260 \\ Universidade Estadual do Oeste do Paraná, Brasil \\ E-mail: thayellen_@hotmail.com
}

\begin{abstract}
Resumo
O presente trabalho tem por escopo a análise do ensino da língua espanhola nas escolas de Ensino Fundamental I na região de Foz do Iguaçu, tendo em vista estar situada em um contexto de fronteiras, e o poder simbólico da língua no contexto dessa região. Inicialmente, a linguagem é observada sob um viés teórico, com uma reflexão quanto ao seu parâmetro de inserção na superestrutura ou na infraestrutura, com observância de sua modulação e alteração através da figura do Estado. Posteriormente, a análise se baseia em uma região de fronteira com o Paraguai e Argentina, países em que a língua majoritariamente falada é o espanhol, de onde se originam dezenas de alunos hispanofalantes, estudantes inseridos nas escolas de Ensino Fundamental I do município de Foz do Iguaçu. A problemática se identifica na ausência de previsão do ensino da língua espanhola na grade curricular municipal, fator que favorece a não inserção social e comunitária, além de não atender as necessidades de inúmeros alunos migrantes da América do Sul que estudam nestas escolas. Ainda, está presente uma contradição no que se refere ao ensino público e o direito à educação de qualidade a todos, dada a ausência de políticas públicas regionais para a promoção da língua espanhola nesse período escolar. Por fim, foi realizado um estudo das disposições da Declaração Universal dos Direitos Linguísticos, considerando a linguagem como um direito fundamental, em especial seu desenvolvimento e fluidez, bem como a sua proteção específica, inclusive no contexto social e estrutural de fronteiras.
\end{abstract}

Palavras-chave: Linguagem; Fronteiras; Língua espanhola; BNCC; Migrantes.

\begin{abstract}
The present work aims to analyze the teaching of the Spanish language in Elementary Schools I in the region of Foz do Iguaçu, considering that it is located in a context of borders, and the symbolic power of the language in the context of this region. Initially, language is observed from a theoretical perspective, with a reflection on its insertion parameter in the superstructure or infrastructure, observing its modulation and alteration through the figure of the State. Subsequently, the analysis is based on a border region with Paraguay and Argentina, countries in which the majority spoken language is Spanish, from which dozens of Spanish-speaking students originate, students inserted in Elementary Schools I in the municipality of Foz do Iguaçu. The problem is identified in the lack of provision for Spanish language teaching in the municipal curriculum, a factor that favors the lack of social and community insertion, in addition to not meeting the needs of countless migrant students from South America who study in these schools. Still, there is a contradiction with regard to public education and the right to quality education for all, given the absence of regional public policies for the promotion of the Spanish language during this school period. Finally, a study of the provisions of the Universal Declaration of Linguistic Rights was carried out, considering language as a fundamental right, especially its development and fluidity, as well as its specific protection, including in the social and structural context of borders.
\end{abstract}

Keywords: Language; Borders; Spanish language; BNCC; Migrants.

\section{Resumen}

El presente trabajo tiene como objetivo analizar la enseñanza de la lengua española en las Escuelas Primarias I de la región de Foz do Iguaçu, considerando que se ubica en un contexto de fronteras, y el poder simbólico de la lengua en el contexto de esta región. Inicialmente, el lenguaje se observa desde una perspectiva teórica, con una reflexión sobre su parámetro de inserción en la superestructura o infraestructura, observando su modulación y alteración a través de la 
figura del Estado. Posteriormente, el análisis se basa en una región fronteriza con Paraguay y Argentina, países en los que la lengua mayoritariamente hablada es el español, de donde proceden decenas de alumnos hispanohablantes, alumnos insertados en las Escuelas Primarias I del municipio de Foz do Iguaçu. El problema se identifica en la falta de dotación de la enseñanza del español en el currículo municipal, factor que favorece la falta de inserción social y comunitaria, además de no atender las necesidades de innumerables estudiantes migrantes de América del Sur que estudian en estas escuelas. Aún así, existe una contradicción en cuanto a la educación pública y el derecho a una educación de calidad para todos, dada la ausencia de políticas públicas regionales para la promoción del idioma español durante este período escolar. Finalmente, se realizó un estudio de las disposiciones de la Declaración Universal de Derechos Lingüísticos, considerando la lengua como un derecho fundamental, especialmente su desarrollo y fluidez, así como su protección específica, incluso en el contexto social y estructural de las fronteras.

Palabras clave: Idioma; Fronteras; Lengua española; BNCC; Migrantes.

\section{Introdução}

O presente trabalho tem como propósito a análise da linguagem, em especial o seu aspecto social, influências e desenvolvimento, no que se refere ao contexto de fronteira. A problemática apresentada no presente trabalho tem por base, em um primeiro momento, analisar se a língua integra a superestrutura ou a infraestrutura do Estado, verificando assim a influência estatal em seu desenvolvimento, bem como a forma em que é influenciada e modulada, através da análise dos pensamentos de Marx, Stalin e Bakhtin. Ademais, a discussão principal se refere à ausência do ensino da língua espanhola nas escolas municipais de Ensino Fundamental I no município de Foz do Iguaçu/PR e os impactos trazidos aos alunos migrantes inseridos nesse contexto. Em um segundo momento, a pesquisa tem por escopo a análise dos argumentos centrais no que tange as normas de proteção à linguística, a análise da língua no contexto de fronteiras, bem como a reflexão da língua como um direito fundamental.

Foz do Iguaçu possui mais de 500 alunos estrangeiros, matriculados nas 51 escolas de Ensino Fundamental I do município. Entre eles, alunos paraguaios, argentinos, venezuelanos e demais países da América Latina. Mas, majoritariamente, crianças migrantes do Paraguai e Argentina por estarem em região de fronteira com o Brasil. Estas crianças, hispanofalantes, que migram para Foz do Iguaçu são matriculadas nas classes regulares sem qualquer tipo de tradução de sua língua materna ou algum tipo de aula que ofereça amparo para o desenvolvimento das relações interpessoais, tampouco que favoreça uma consciência de comunicação entre as duas línguas. Pelo contrário, são impostas aos alunos regras de codificação e decodificação de uma língua que eles não conhecem, além de serem avaliados de acordo com a regra dos códigos linguísticos da nova língua.

O Estado, neste caso, representado pela Secretaria Municipal de Educação teria de desempenhar uma forma de inserção dessa língua no currículo escolar, já que o espanhol é uma língua falada em todo o território de fronteira a fim de formar uma estrutura social de interação e formação de uma significação e identidade territorial.

Entretanto, com a implementação da Base Nacional Comum Curricular (BNCC) no currículo do Ensino Fundamental I, a língua estrangeira contemplada no currículo é a língua inglesa. Sem dúvidas, o inglês é importante numa região com diversas etnias que falam a língua inglesa, porém, na realidade do nosso território, o ensino da língua possui apenas finalidades econômicas, tendo em vista que a língua estrangeira predominante na região é o espanhol. As questões de relação, comunicação e sociabilidade que acontecem entre moradores da fronteira que se deslocam neste território, se dá a partir do espanhol, que deveria ser a língua estrangeira estudada na escola a partir do Ensino Fundamental I, não só para os migrantes, mas para todas as crianças que tem contato com a língua através da interação com os demais colegas e no cotidiano de fronteira.

Este artigo não tem intenção de determinar um modelo de currículo ou de disciplinas para as escolas do município, mas refletir sobre o papel da língua na interação e na integração de nossos alunos migrantes, que demonstram muitas dificuldades de pertencimento, comunicação e apreensão do conteúdo numa escola que delimita e impõe o padrão de linguagem dominante.

Diante dessa realidade, em seguida, a presente pesquisa se dedica ao estudo das normas legais internacionais de proteção à língua, em especial a Declaração Universal dos Direitos Linguísticos, efetivados como direitos individuais e coletivos. Nesse 
momento, foi feita uma breve análise da língua, com enfoque específico no contexto de fronteiras e suas pluralidades. A proteção linguística é analisada como direito fundamental do cidadão inserido em qualquer comunidade.

Tendo em vista a porosidade das fronteiras, a pesquisa desenvolvida tem como objeto central estabelecer uma análise dos aspectos da linguagem em um contexto fronteiriço, verificando os parâmetros e limites linguísticos e culturais estabelecidos, tendo em vista a pluralidade linguística destas regiões, observada a proteção humanística inerente à língua e ao indivíduo.

Dessa maneira, a reflexão trazida no presente trabalho tem por objetivo delimitar o estudo da linguagem como um fenômeno inserido na superestrutura ou na infraestrutura do Estado, de acordo com o as teorias de Marx, Stalin e Bakhtin, avaliando a influência estatal em seu desenvolvimento; identificar e analisar o desenvolvimento da linguagem em contexto de fronteiras, em especial no que se refere ao ensino da língua espanhola no Ensino Fundamental I, no município de Foz do Iguaçu/PR; analisar os mecanismos de proteção à língua, em especial o disposto na Declaração Universal dos Direitos Linguísticos; verificar a proteção humanística adotada pelas normas de proteção internacional à língua, inclusive em um contexto de fronteiras.

\section{Metodologia}

O presente artigo tem como base a metodologia qualitativa, partindo da perspectiva de Lüdke \& André (1986), com uma "investigação passando por três etapas: exploração, decisão e descoberta" (p. 15). A pesquisa iniciou com observação direta no primeiro momento a fim de conhecer o fenômeno da investigação e posteriormente foi realizado reflexão teórica a respeito do poder simbólico da linguagem em um contexto de fronteiras, mais especificamente no contexto da tríplice fronteira, a qual abrange a interação entre Brasil, Argentina e Paraguai, com enfoque no que se refere ao ensino da língua espanhola nas escolas municipais de Foz do Iguaçu/PR, que é o problema deste artigo.

A primeira fase da pesquisa aconteceu mediante observação da realidade das escolas municipais de Foz do Iguaçu/PR, concernente aos alunos migrantes hispanofalantes e sua inclusão no cotidiano escolar. De acordo com Lüdke \& André, "Nessa etapa inicial também estão incluídas as primeiras observações, com a finalidade de adquirir maior conhecimento sobre o fenômeno e possibilitar a seleção de aspectos que serão mais sistematicamente investigados” (1986, p. 15), a observação direta dessas escolas durante um longo período nos orientaram no levantamento de material para o embasamento teórico da defesa da hipótese levantada durante a investigação. Na segunda fase, procuramos sistematizar o problema da pesquisa com embasamento teórico fundamentado através de pesquisa bibliográfica, mediante artigos científicos publicados em revistas, assim como livros, publicações online e materiais apresentados em congressos, com o intuito de obter maior compreensão e verificação do entendimento dos pesquisadores quanto ao tema. Ainda, foram analisados a Base Nacional Comum Curricular (BNCC) e a Declaração Universal dos Direitos Linguísticos, trazendo o enfoque da pesquisa para o contexto de fronteiras.

$\mathrm{Na}$ terceira fase ou terceiro estágio buscamos relacionar a realidade observada com as bibliografias encontradas sobre o tema com a finalidade de encontrar uma explicação para o contexto observado. Segundo Lüdke \& André, "esta fase envolve o desenvolvimento de teorias, um processo que vai sendo preparado durante todo o desenrolar do estudo" (1986, p. 16). Isto é, nesta fase foi possível entender melhor a teoria criada a partir da observação mediante evidências estudadas durante todo a pesquisa.

\section{Resultados e Discussão}

Primeiramente, é necessário abordar a ideologia para então chegar a linguagem. Diante da brevidade do presente artigo, serão analisadas apenas as visões de Marx, Stalin e Bakhtin no que tange à linguagem e suas teorias estruturais.

Importante destacar que o presente estudo não tem por intuito esgotar todas as teorias e debates disponíveis a respeito do tema, apenas contextualizar o considerado necessário para realização da análise aqui proposta. 
Deste modo, observa-se, inicialmente, que ideologia e linguagem possuem relações extremamente estreitas. Para Marx, a ideologia é um fator crucial para o desenvolvimento social e político, integralizando a superestrutura. Neste sentido, Marx analisa a linguagem como mecanismo ideológico e de classe.

Contudo, Stalin apresenta uma visão divergente no que tange à linguagem, tendo em vista que não considera o fato da língua estar inserida em uma relação ideológica de classe, servindo de diversas maneiras a distintas classes sociais (Costa, 2000, p. 45). Stalin não considerou, portanto, a linguagem como superestrutura, tampouco analisou a luta de classes como fator importante para o seu desenvolvimento.

Para Bakhtin, no entanto, em contraposição ao pensamento de Stalin, - que, conforme exposto, não considerava que a língua estava inserida na superestrutura nem em um sistema ideológico - apresenta uma visão mais crítica a respeito da linguagem e sua relação com a ideologia, considerando que a palavra é a maior representação sinalética da ideologia:

[...] o lugar da realização do ideológico na linguagem não está na língua como um sistema abstrato de formas, mas no signo lingüístico, na palavra. Para mostrar isto, Bakhtin utiliza um conceito de ideologia bastante amplo. Ideologia, para ele, além de designar as manifestações culturais em geral, diz do que é relativo a índices de valor que se confrontam, determinados pelos conflitos de interesses sociais. Nesse sentido, para ele, todo signo é ideológico, pois está sujeito a critérios de avaliação (se é verdadeiro ou falso, correto ou incorreto, justificado ou não, bom ou ruim etc.) (Costa, 2000, p. 46).

Assim, através da análise da palavra, Costa destaca uma das maiores peculiaridades do pensamento de Bakhtin no que tange ao estudo linguístico: considera que a palavra está inserida ao mesmo tempo na superestrutura e na infraestrutura.

[...] é que a palavra, estando presente tanto na infra-estrutura quanto na superestrutura, não é nem uma nem outra: de um lado, ela é condicionada pela organização social dos indivíduos, refletindo e refratando a realidade material dessa organização (infra-estrutura); de outro, ela possui sempre um índice de valor social, o que a insere no domínio da ideologia (superestrutura) (Costa, 2000, p. 47).

Portanto, evidente que, para o autor, a linguagem possui um valor intrinsecamente social, não podendo ser considerada uma partícula específica nem de uma nem de outra, integralizando ambas concomitantemente.

Por meio de uma análise materialista dialética, no entanto, a história da linguagem não é considerada apenas uma sucessão de acontecimentos temporais ou mecânicos, tendo em vista que o materialismo dialético prima pela valoração da análise histórica como resultado do trabalho humano, ao longo de toda a sua organização social (Costa, 2000, p. 51).

Desta maneira, diante da breve análise aqui realizada, considera-se que a linguagem é fruto da interação social humana, transpassando o viés político e ideológico, sendo necessária para a formação e desenvolvimento social e comunitário, estando assim inserida, ao mesmo tempo, na superestrutura e na infraestrutura, sendo desenvolvida e influenciada de forma direta, concomitante e constante uma pela outra.

Nesse sentido, trazemos no presente trabalho reflexões e questionamentos a respeito do papel da escola no ensino da linguagem, tendo em vista que esta atua como um mecanismo que compõe a superestrutura e a infraestrutura da sociedade. Segundo Althusser, a escola é uma instituição de "reprodução das relações de produção, isto é, das relações de exploração capitalista" (Althusser, 1985, p. 78), e que durante anos a assimilação das ideias dominantes acontece de forma planejada, sistematizada, durante 5 dias na semana por 4 horas, no mínimo. Ou seja, a escola não está alheia à sociedade de classes, antes é um instrumento de reprodução das "relações de produção de uma formação social capitalista, ou seja, as relações entre exploradores e explorados e entre explorados e exploradores" (Althusser, 1985, p.80). 
A escola, que deveria ser um instrumento de humanização, a formação de um homem omnilateral ${ }^{1}$, é na verdade uma escola unilateral e alienadora, que forma o homem para atender as divisões pormenorizadas do trabalho que o capital necessita. Além de que, confirma e reproduz a sociedade de classes quando existem escolas diferenciadas para os filhos da classe trabalhadora e para os filhos dos dirigentes, ou seja, formando a classe subalternizada em mão de obra para o trabalho técnico e utilitário e os filhos da classe dominante para as atividades intelectuais e de comando, aumentando cada vez mais a distância da classe trabalhadora para a classe dominante.

A problemática linguística surge no contexto fronteiriço, tendo em vista de que é um local de interação, cruzamento e convívio entre idiomas e pessoas. A fronteira e suas práticas linguísticas possuem características peculiares, dado o contato diário com os países vizinhos, que possuem língua materna diversa.

\section{Conforme preceitua Eliana Rosa Sturza,}

A fronteira do Brasil com esses países é caracterizada por zonas de grande concentração populacional, como o sul do Brasil, e outras marcadas por obstáculos geográficos naturais, caso do norte do país, onde existem zonas praticamente vazias de presença humana. De qualquer modo, mesmo onde os agrupamentos são menores e menos populosos, a fronteira efetivamente é complexa pela natureza de sua formação e pelo modo como se estabelecem ali as relações sociais das diferentes etnias que nela habitam. As fronteiras geográficas são preenchidas de conteúdo social. Se as fronteiras são sociais, se nelas vivem diferentes etnias - índios, espanhóis, árabes, portugueses, alemães, entre outros o contato linguístico é uma consequência inevitável, e a situação das práticas linguísticas nessas regiões, de um modo geral, um campo pouco explorado pela linguística brasileira (Sturza, 2005, p. 47).

Assim, observa-se que a fronteira, em especial, possui um conteúdo social, diante das diferentes etnias e práticas linguísticas que a compõem. É um espaço considerado "desterritorializado", possibilitando o contato entre culturas e idiomas que partilham fronteiras geográficas (Sturza, 2005, p. 48), ultrapassando os limites idiomáticos estabelecidos e adotados oficialmente por cada um dos estados.

Desta forma, a miscigenação linguística é inevitável, corroborando com a adoção de uma língua não oficial, constituindo assim uma nova forma de linguagem, materializada pela natureza das relações estabelecidas.

Neste sentido, Sturza salienta:

O cruzamento das línguas, resultando em uma outra prática linguística não nacional e não-oficial, significa na materialidade linguística a própria natureza das relações entre línguas, em que formas são tomadas de empréstimo; sentidos de uma língua são apropriados pela outra língua e novos dizeres se constituem. Portanto, o cruzamento de línguas só pode se constituir e significar no Espaço de Enunciação Fronteiriço (Sturza, 2006, p. 76).

É neste contexto social em que surgem os hibridismos linguísticos, a criação e adoção de miscelâneas idiomáticas, como o chamado "portunhol", na tentativa de adaptação local às diferenças da língua.

Importante evidenciar, neste contexto, as considerações de José Lindomar Albuquerque, no que tange à realidade de fronteira, mais especificamente, na fronteira entre Brasil, Argentina e Paraguai. No trecho a seguir, o autor demonstra a realidade social diária dos indivíduos que habitam ou transitam pela tríplice fronteira:

Ouvidos atentos para escutar as línguas das fronteiras, os sons das línguas no comércio de Ciudad del Este podem traduzir a zona de transição entre o Brasil e o Paraguai na própria geografia do comércio fronteiriço. Entre a Ponte da Amizade e o primeiro trevo de Ciudad del Este, observamos as misturas da língua portuguesa, espanhola, guarani e árabe ou chinesa em diferentes tonalidades conforme as ruas e lojas comerciais. Há vendedores de lojas em Ciudad del Este que falam espanhol ou guarani com os clientes paraguaios e argentinos, português ou "portunhol" com os brasileiros e árabe com os patrões. Os quatros idiomas podem ser manejados em uma mesma situação de compra e

\footnotetext{
${ }^{1}$ Omnilateralidade é "a chegada histórica do homem a uma totalidade de capacidades produtivas e, ao mesmo tempo, a uma totalidade de capacidades de consumo e prazeres, em que se deve considerar sobretudo o gozo daqueles bens espirituais, além dos materiais, e dos quais o trabalhador tem estado excluído em consequência da divisão do trabalho" (Manacorda, 2007, p. 89).
} 
venda de mercadorias. Além da situação linguística no comércio fronteiriço, é importante também pontuar a presença das línguas de fronteira nas cidades e colônias de imigração brasileira no Paraguai, na programação televisiva e nas rádios e suas ondas sonoras na região de fronteiras, além das músicas e festas que atravessam, singularizam, subvertem e reproduzem as relações sociais nessa zona fronteiriça (Albuquerque, 2014, p. 67).

Desta maneira, diante de toda análise realizada no presente estudo, considera-se que a linguagem no contexto de fronteira possui um caráter heterogêneo e supranacional, estando presentes concomitantemente, diversos idiomas e culturas em contextos rotineiros. Neste sentido, considera-se que a linguagem ultrapassa as barreiras sociopolíticas, geográficas e ideológicas estabelecidas, alcançando um paradigma de interação social histórico e regional configurados pela diversidade de línguas e culturas.

Surge então a problemática central da presente discussão: a análise do ensino linguístico na região de fronteiras, bem como o currículo da escola na área de línguas estrangeiras, mais especificamente, das escolas de Foz do Iguaçu e suas mudanças por conta da Base Nacional Comum Curricular - BNCC e o alinhamento desta ao mercado e a formação dos alunos para o mundo do trabalho, no qual não é dado enfoque para o ensino da língua espanhola.

No início do ano letivo de 2020 foram feitas muitas mudanças na organização e planejamento escolar das escolas municipais de Foz do Iguaçu, principalmente nas formações continuadas de professores se tratando sobre a implementação do novo currículo trimestral alinhado com a BNCC para o Ensino Fundamental I conforme o "art. $15^{\circ}$ da Resolução CNE/CP n 2/2017 [que] deixa explícito que a adequação do currículo à BNCC deve ser efetivada, preferencialmente, em 2019, podendo se estender, no máximo, até o início de 2020” (Brasil, 2019).

Referido documento, que tem por objetivo servir de referencial e base curricular em todo o território nacional, tem como enfoque principal as competências e habilidades, a fim de preparar os alunos para o mercado de trabalho e para as provas em larga escala. Segundo o documento: "Na BNCC, competência é definida como a mobilização de conhecimentos (conceitos e procedimentos), habilidades (práticas, cognitivas e socioemocionais), atitudes e valores para resolver demandas complexas da vida cotidiana, do pleno exercício da cidadania e do mundo do trabalho (Brasil, 2017, p. 10).”

O documento deixa explícito seu caráter de formação de mão-de-obra para o mercado de trabalho, pois, em todo o documento faz referências da necessidade de aprimoramento das habilidades tecnológicas para atender as modernizações do mundo do trabalho. Além de que as declarações do ex-ministro da educação no ano de 2017 destaca a formação de habilidades necessárias para a competitividade numa lógica meritocrática. Esta é a fala do ex-ministro Rossieli Soares numa palestra aos diretores da Confederação Nacional da Indústria (CNI):

“A discussão com a CNI é importantíssima. A entidade tem força para a condução não só da indústria, mas também da economia brasileira e da geração de empregos [...] Precisamos ouvi-los e saber se o que estamos fazendo na educação ajuda a comunicar, a dar empregabilidade ao jovem e se dá a competitividade que precisamos ter [...] Se a nossa mão de obra, os nossos jovens cada vez mais saírem com as competências do Século 21, com tudo aquilo que o mundo inteiro tem feito, a nossa competitividade vai aumentar e teremos maior empregabilidade no Brasil.” 2

Infelizmente, quando o documento fala de novas competências para o aumento da competitividade e da empregabilidade, fala do aumento do emprego precarizado do século XXI, onde os trabalhadores são obrigados a terem um trabalho cada vez mais estranhado, dado que o Estado não oferece o mínimo de emprego. Outro aspecto da BNCC é seu foco nas avaliações externas e no cumprimento de metas para a justificativa de privatização e meritocracia. Em seu documento deixa claro que o enfoque sobre habilidades e competências é por conta das provas em larga escala que já adotaram esse perfil.

De acordo com o documento:

2 Ministério da Educação (2018). Ministro conversa sobre educação com representantes da indústria. http://portal.mec.gov.br/com ponent/content/article?id=69211. 
[...] desde as décadas finais do século XX e ao longo deste início do século XXI, o foco no desenvolvimento de competências tem orientado a maioria dos Estados e Municípios brasileiros e diferentes países na construção de seus currículos. É esse também o enfoque adotado nas avaliações internacionais da Organização para a Cooperação e Desenvolvimento Econômico (OCDE), que coordena o Programa Internacional de Avaliação de Alunos (Pisa, na sigla em inglês), e da Organização das Nações Unidas para a Educação, a Ciência e a Cultura (Unesco, na sigla em inglês), que instituiu o Laboratório Latino-americano de Avaliação da Qualidade da Educação para a América Latina (Brasil, 2017, p. 13).

O resultado da implantação da BNCC na educação é um só: a transformação da escola num aparelho que represente ainda mais a classe hegemônica, interessada na formação de trabalhadores para suprir as necessidades do mercado. Se olharmos pelo viés mercadológico da BNCC podemos analisar a escolha do inglês como a única língua estrangeira como uma correspondência da globalização e da necessidade de o trabalhador ter condições de responder à "empregabilidade" do capitalismo.

Segundo o documento, a primeira competência a ser desenvolvida com a língua inglesa no Ensino Fundamental é: "Identificar o lugar de si e o do outro em um mundo plurilíngue e multicultural, refletindo, criticamente, sobre como a aprendizagem da língua inglesa contribui para a inserção dos sujeitos no mundo globalizado, inclusive no que concerne ao mundo do trabalho (Brasil, 2017, p. 246).”

O objetivo acima elencado explica a exclusão do ensino do espanhol do currículo, pois, mesmo o Brasil fazendo fronteira, majoritariamente, com países hispanofalantes em todo o nosso território nacional, além de receber migrantes de toda a América do Sul, o espanhol não é considerado economicamente necessário para ser estudado desde o Ensino Fundamental, pois, segundo o documento a língua necessária para a inserção dos sujeitos no mundo do trabalho cada vez mais globalizado é o inglês.

Este é um debate muito mais necessário em cidades que fazem fronteiras com os países que tem o espanhol como língua oficial, pois, são territórios de culturas pluriétnicas com mais de uma língua falada, como é o caso de Foz do Iguaçu, que faz fronteira com a cidade de Puerto Iguazu na Argentina e Ciudad del Este no Paraguai e que tem uma interação intercultural por conta dos indivíduos dos três países que atravessam a fronteira todos os dias para estudar, trabalhar e se relacionar com a cultura do outro país formando uma identidade plural.

Entretanto, não existe um empenho local para criação de políticas públicas de interrelações desses migrantes, principalmente na educação. É como descreve Roberto Cardoso de Oliveira sobre migrantes de outras nacionalidades que vivem em outro Estado-nação em que a sociedade anfitriã é culturalmente hegemônica e dominante:

[...] a estrutura das relações interétnicas, inerente às sociedades hospedeiras, é muitas vezes fortemente institucionalizada. E que tais relações [...] estão reguladas tanto in mores quanto in juris, o que lhes confere grande peso na configuração das relações de imigrantes de diferentes nacionalidades e/ou etnias junto à população nativa, isto é, do lugar (Oliveira, 2000, p. 9).

Os migrantes residentes em outras sociedades geralmente são obrigados a adequar sua existência a novas culturas, pois, quem define e determina as "regras do jogo identitário" (Oliveira, 2000, p. 9) é a sociedade anfitriã. Além de que suas instituições contribuem para a estigmatização, como é o caso da escola, que recebe inúmeros alunos falantes do espanhol, mas que não se adequa a inserir sua cultura e identidade no cotidiano escolar ou mesmo ajudando-o com a nova língua.

No caso dos alunos migrantes do Paraguai e Argentina, além de inúmeros alunos migrantes da Venezuela, a importância da disciplina de espanhol no Ensino Fundamental I também é pela contextualização de sua língua para os demais alunos brasileiros e a inclusão desta nos contextos escolares, a fim de, os alunos brasileiros, não só aprenderem as normas de uma nova língua, mas interagirem e se apropriarem da cultura e da identidade dos alunos falantes do espanhol. O ensino da língua espanhola contribui para que não exista uma barreira caracterizada pela língua entre os moradores do mesmo território - e que utilizam as 
mesmas instituições de ensino - e para que não exista uma distinção social causada pela hostilidade da sociedade anfitriã, estabelecendo um padrão de comunicação pautado em sua língua materna.

\section{Segundo Bourdieu:}

A língua oficial está enredada com o Estado, tanto em sua gênese como em seus usos sociais. É no processo de constituição do Estado que se criam as condições da constituição de um mercado linguístico unificado e dominado pela língua oficial: obrigatória em ocasiões e espaços oficiais (escolas, entidades públicas, instituições políticas etc.), esta língua de Estado torna-se a norma teórica pela qual todas as práticas linguísticas são objetivamente medidas. Ninguém pode ignorar a lei linguística que dispõe de seu corpo de juristas (os gramáticos) e de seus agentes de imposição e de controle (os professores), investidos do poder de submeter universalmente ao exame e à sanção jurídica do título escolar o desempenho linguístico dos sujeitos falantes (Bourdieu, 2008, p. 32).

A escola, enquanto instituição do Estado, tem o controle de imposição da língua que será usada, e de que forma essa língua e seu sistema de escrita será avaliado. A imposição de uma língua padrão na escola faz sentido aos falantes da língua oficial daquele país que tem necessidade de se apropriar do código para seu uso social, entretanto, para alunos estrangeiros que ainda não se apropriaram da língua e seu sistema, é uma forma de exclusão e aumento da disparidade entre a aprendizagem de um aluno brasileiro com a de um estrangeiro.

A imposição de uma língua estrangeira através de única opção de ter acesso à educação e a obrigação de se adequar a ela, mesmo estando em um território onde sua língua materna é amplamente usada, é uma forma de legitimar a ideia de que existe uma língua padrão, superior e correta naquele determinado território. Ou seja, é a desvalorização de uma língua em detrimento a outra pelo próprio sistema de ensino.

Conforme já analisado, a linguagem é uma forma de desenvolvimento humano, social e cultural, possuindo um caráter específico e autônomo. Desta maneira, diante da necessidade de uma tutela específica para proteção da língua - de forma abrangente, alcançando toda e qualquer língua falada - surge a Declaração Universal dos Direitos Coletivos dos Povos, com o intuito de concretizar o disposto na Declaração Universal dos Direitos Humanos, estabelece que todos os povos possuem o direito de expressar, manifestar e desenvolver sua respectiva cultura, língua e normas de organização.

Partindo dessa premissa, tendo em vista que grande parte das línguas ameaçadas não vem de países ou comunidades soberanas, existem diversos fatores sociais e políticos que impedem o seu desenvolvimento, como por exemplo: “a ausência de autogoverno e a política de Estados que impõem a sua estrutura político-administrativa e a sua língua" (Unesco, 1996).

Ademais, a Declaração Universal dos Direitos Linguísticos atua como forma de proteção aos idiomas de países invadidos, colonizados e ocupados, dado que em sua grande parte, passam por um processo de substituição linguística, sobrevindo a adoção do idioma de seus colonizadores.

Considerando que a invasão, a colonização e a ocupação, assim como outros casos de subordinação política, econômica ou social, implicam frequentemente a imposição direta de uma língua estrangeira ou a distorção da percepção do valor das línguas e o aparecimento de atitudes linguísticas hierarquizantes que afetam a lealdade linguística dos falantes; e considerando que, por esses motivos, mesmo as línguas de alguns povos que acederam à soberania se confrontam com um processo de substituição linguística decorrente de uma política que favorece a língua das antigas colônias e das antigas potências colonizadoras (Unesco, 1996).

Referida declaração tem o condão de estabelecer um equilíbrio linguístico, de maneira igualitária, visando o desenvolvimento de toda e qualquer língua, independentemente de sua soberania ou hierarquia social.

Seu artigo $3^{\circ}$ estabelece que o reconhecimento como membro de uma comunidade linguística, bem como o direito de uso da linguagem, do próprio nome e de relacionar-se com outros membros de sua comunidade linguística são direitos individuais inalienáveis. 
Artigo 3..$^{\circ}$. Esta Declaração considera como direitos individuais inalienáveis que devem ser exercidos em todas as situações os seguintes: o direito a ser reconhecido como membro de uma comunidade linguística; o direito ao uso da língua em privado e em público; o direito ao uso do próprio nome; o direito a relacionar-se e associar-se com outros membros da comunidade linguística de origem; o direito a manter e desenvolver a própria cultura; e todos os outros direitos de caráter linguístico reconhecidos no Pacto Internacional de Direitos Civis e Políticos de 16 de Dezembro de 1966 e no Pacto Internacional de Direitos Econômicos, Sociais e Culturais da mesma data (Unesco, 1996).

Por essa lógica, os direitos linguísticos são abordados como direitos fundamentais de cada cidadão, da comunidade em que está inserido, bem como, ultrapassando as barreiras geográficas existentes, a declaração ampara "o espaço social e funcional indispensável ao pleno desenvolvimento da língua" (Unesco, 1996, p.04), possibilitando que aqueles que não residam ou estejam inseridos em sua comunidade linguística originária também possam ser assistidos.

Os direitos fundamentais são tutelados pela constituição e são inerentes ao cidadão, objetivando que este se desenvolva em sociedade com dignidade. No entanto, os direitos fundamentais não são absolutos e sim relativos. Alexandre de Moraes (2017, p. 44) assim define: “os direitos e garantias fundamentais [...] não são ilimitados, uma vez que encontram seus limites nos demais direitos igualmente consagrados pela Carta Magna”, desta forma, caso ocorra conflito entre direitos ou garantias fundamentais o intérprete precisa aplicar o princípio da concordância prática ou da harmonização, visando impedir o sacrifício absoluto de um direito (Moraes, 2017, p. 44).

Quanto aos destinatários desses direitos, sua proteção está voltada para todos aqueles que transitam ou habitam no território nacional, conforme o artigo $5^{\circ}$, todos têm direito à vida, liberdade, igualdade, segurança e propriedade. Os direitos e garantias fundamentais estão previstos no título II da Constituição Federal, com cinco subdivisões: direitos individuais e coletivos; direitos sociais; nacionalidade; direitos políticos e partidos políticos (Moraes, 2017, p. 44).

Eles são classificados como direitos de primeira, segunda e terceira gerações, seguindo os ideais franceses de liberdade, igualdade e fraternidade, como define Alexandre de Moraes:

[...] modernamente, a doutrina apresenta-nos a classificação de direitos fundamentais de primeira, segunda e terceira gerações, baseando-se na ordem histórica cronológica em que passaram a ser constitucionalmente reconhecidos. Como destaca Celso de Mello, "enquanto os direitos de primeira geração (direitos civis e políticos) - que compreendem as liberdades clássicas, negativas ou formais - realçam o princípio da liberdade e os direitos de segunda geração (direitos econômicos, sociais e culturais) - que se identificam com as liberdades positivas, reais ou concretas - acentuam o princípio da igualdade, os direitos de terceira geração, que materializam poderes de titularidade coletiva atribuídos genericamente a todas as formações sociais, consagram o princípio da solidariedade e constituem um momento importante no processo de desenvolvimento, expansão e reconhecimento dos direitos humanos, caracterizados enquanto valores fundamentais indisponíveis, pela nota de uma essencial inexauribilidade" (Moraes, 2017, p. 44).

Além dos dispositivos protetivos encontrados no ordenamento jurídico nacional, os tratados internacionais ratificados pelo Brasil também são fonte de direitos fundamentais, um deles é o Tratado de Direitos Humanos (Viegas \& Nascimento, 2015, p. 5).

Viegas e Nascimento (2015, p. 5-6) destacam que: "dessa forma, os direitos fundamentais têm diversas características, como a universalidade, que pertence a todos os cidadãos que estão ao alcance da constituição”.

Em relação ao conceito de direitos humanos, são uma categoria conglobada pelos direitos fundamentais positivados pela constituição de determinado país. Portanto, diferem dos direitos fundamentais em si, tendo em vista que estes são mais amplos. No entanto, abrangem todas as prerrogativas, instituições e bens jurídicos que de especial maneira amplificam o princípio da Dignidade da Pessoa humana com o ideal de uma sociedade que dê suporte à existência fraterna e solidária em meio aos cidadãos.

Neste sentido, visando analisar a linguística em um contexto de fronteiras, destaca-se aqui a proteção da língua e da cultura de cada indivíduo inserido - de forma transitória ou não - em um contexto fronteiriço, diante da noção de que o direito 
ao uso, reconhecimento e desenvolvimento da linguagem são inerentes ao homem, possuindo caráter de direito fundamental. Nesse sentido, são consideradas necessárias e urgentes as políticas públicas que visam o ensino e a difusão da língua espanhola na região de Foz do Iguaçu/PR, dado que o idioma é essencial para o desenvolvimento social, a integração e a permanência do indivíduo inserido no contexto de fronteira, sendo primordial a valorização da língua espanhola.

\section{Considerações Finais}

Foram analisados, inicialmente, os pensamentos de Marx, Stalin e Bakhtin, no que se refere superestrutura e infraestrutura, no que tange aos estudos da linguística. Através da referida análise, constatou-se que a língua está inserida concomitantemente em ambos os sistemas, de modo que influencia tanto na luta de classes como na formação ideológica, estando presente em todos os sistemas e classes possíveis, de forma homogênea e sistemática, sendo um fator primordial para o desenvolvimento humano e social, possuindo assim autonomia, característica própria de sua especificidade.

Neste sentido, diante de seu caráter específico, a Declaração Universal dos Direitos Linguísticos, com condão protetivo, estabelece que todos os povos possuem o direito de expressar, manifestar e desenvolver sua respectiva cultura, língua e normas de organização. No presente trabalho, foram consideradas as línguas em um contexto de fronteiras e a sua necessidade de proteção, tendo em vista a porosidade fronteiriça, bem como a adoção de idiomas diversos nestas localidades.

Diante de todo o estudo realizado, conclui-se que a linguagem no contexto de fronteira possui um caráter heterogêneo e supranacional, ultrapassando assim as barreiras sociopolíticas, geográficas e ideológicas estabelecidas, tornando-se resultado de uma interação social histórica e regional configurada pela diversidade de línguas e culturas.

Esta análise em torno da exclusão do espanhol do currículo da escola de fronteira nos leva a ver a escola que está posta, como uma escola interessada somente nos objetivos que vemos na BNCC: na formação de mão-de-obra adequada ao mundo do trabalho e nos resultados das avaliações externas de larga escala. Pois, a discussão sobre a necessidade de aulas de espanhol no município entre educadores e pesquisadores que pensam sobre a fronteira já vem de longa data, e, mesmo assim a língua implementada é o inglês.

A valorização de uma língua em detrimento a outra e a hierarquização desta só aumenta a desigualdade entre os alunos brasileiros e estrangeiros, sendo necessária a reflexão do ensino de linguagens especificamente no contexto de fronteiras, possibilitando a inclusão e evitando que além de não terem acesso ao ensino efetivamente por conta da diferença linguística, os sujeitos não se reconheçam e não se sintam pertencentes a escola, já que a mesma não valoriza e não aborda sobre suas culturas.

Estando numa democracia, mesmo que representativa, é legítima e necessária a luta pela não violação de direitos e pelo caráter universal da escola pública. É necessário refletir a respeito das peculiaridades regionais e sobre o incentivo de políticas públicas fronteiriças que possam integrar a região. O poder presente no uso e desuso da língua materna de nossos alunos pode definir barreiras num território em que a fronteira física não interfere no acesso à educação, mas as fronteiras impostas na língua pela escola definem, excluem e segregam.

Nosso intuito não é esgotar o tema, mas, provocar mais reflexões sobre o direito linguístico do migrante, propondo mais discussões acerca do ensino de línguas na escola pública, principalmente o ensino da língua espanhola, uma vez que é a língua majoritária dos países que fazem fronteira com o Brasil. As pesquisas que tratam da escola inclusiva, de igual acesso e permanência para todos, devem tratar, sobretudo, dos alunos hispanofalantes que muitas vezes não se sentem com igual acesso aos demais alunos por conta da barreira linguística proposta pelo currículo base nacional.

\section{Referências}

Albuquerque, J. (2014). Fronteiras: Entre os caminhos da observação e os labirintos da interpretação. Unbral Fronteiras, pp. 61-80. http://unbral.nuvem.ufrgs.br/base/items/show/3854. 
Research, Society and Development, v. 10, n. 10, e515101019169, 2021

(CC BY 4.0) | ISSN 2525-3409 | DOI: http://dx.doi.org/10.33448/rsd-v10i10.19169

Albuquerque, J. L. (2010). Conflito e integração nas fronteiras dos "brasiguaios". Caderno CRH [online], 23(60), 79-590. https://doi.org/10.1590/S010349792010000300009 .

Althusser, L. (1985). Aparelhos Ideológicos do Estado. Conselho Editorial.

Bakhtin, M. (2010). Marxismo e Filosofia da Linguagem - problemas e fundamentos do método sociológico na ciência da linguagem. Hucitec.

Bourdieu, P. (2008). A Economia das trocas linguísticas. Edusp.

Brasil (1988). Constituição da República Federativa do Brasil. http://www.planalto.gov.br/ccivil_03/constituicao/constituicao.html.

Brasil (2017). Ministério da Educação. Base nacional comum curricular. http://basenacionalcomum.mec.gov.br.

Brasil (2019). Ministério da Educação. Perguntas frequentes ProBNCC. http://basenacionalcomum.mec.gov.br/images/implementacao/perguntas_freque ntes_bncc.pdf.

Cardin, E. G., \& Colognese, S. A. (orgs.) (2014). As Ciências Sociais nas fronteiras: teorias e metodologias de pesquisa. Unbral Fronteiras.

Costa, N. B. (2000). Contribuições do Marxismo para uma teoria crítica da linguagem. Revista DELTA: documentação de estudos em linguística e teórica aplicada [online], 16(1), 27-54. https://doi.org/10.1590/S0102-44502000000100002.

Gramsci, A. (1989). Os intelectuais e a organização da cultura. Civilização Brasileira.

Ludke, M., \& André, M. E. D. A. (1986). Pesquisa em educação: uma abordagem qualitativa. EPU.

Manacorda, M. A. (2007). Marx e a pedagogia moderna. Tradução Newton Ramosde-Oliveria. Campinas, São Paulo: Alínea.

Marx, K. (2007). A Ideologia Alemã. Boitempo Editorial.

Moraes, A. (2017). Direito Constitucional. 33. Atlas.

Oliveira, R. C. (2000). Os (des)caminhos da identidade. Revista Brasileira De Ciências Sociais, 15(42), 07-21. https://doi.org/10.1590/S010269092000000100001.

ONU (1948). Declaração Universal Dos Direitos do Homem e do Cidadão. Organização das nações unidas.

Sturza, E. R. (2006). Línguas de fronteira e política de línguas: uma história das ideias linguísticas. http://repositorio.unicamp.br/jspui/handle/REPOSIP/270606.

Sturza, E. R. (2005). Línguas de fronteira: o desconhecido território das práticas lingüísticas nas fronteiras brasileiras. Ciência e Cultura, 57(2), 47-50. http://cienciaecultura.bvs.br/scielo.php?script=sci_arttext\&pid=S0009-67252005000200021\&lng=en\&tlng=pt.

UNESCO (1996). Declaração Universal dos Direitos Linguísticos. Unesco.

Viegas, C. M. A. R., \& Nascimento, U. D. (2015). A eficácia horizontal dos direitos fundamentais às relações privadas. Uniesp. http://uniesp.edu.br/sites/_biblioteca/revistas/20170728105436.pdf. 